\title{
Transforming A Good Institution Into Greatness
}

\section{Sreeharan $N^{1}$}

\section{${ }^{1}$ Visiting Professor, Department of Clinical Medicine, University of Jaffna}

Email: nsreeharan@gmail.com

https://orcid.org/0000-0002-4839-6804

(Edited version of the Chief Guest's address at the JMA Annual Sessions 2018)

Mr Chairman, Members of the Jaffna Medical Association, Ladies \& Gentlemen, let me at the outset thank the JMA for granting me this privilege of being the Chief Guest at this year's Annual Academic Session. JMA was an integral part of my period in Jaffna. I left Jaffna with a very heavy heart and although I had moved physically to the UK my heart had always remained here. Indeed, when the Indian Peace Keeping Forces arrived, at the request of non-other than Prof Sivagnanasunderam, whom we are honouring today with an oration, I Ittempted to return to Jaffna, but the rest is history. The hostilities resumed and my attempt was aborted. Third time around, I am grateful to the Faculty for inviting me back in a formal visiting position and I hope I could be of some help in capacity building exercises here.

Not that you need my help. Despite three decades of civil strife, it is a testimonial to every one of you that medical education and the delivery of healthcare is in a good space. I can only speak for specialties that are close to my own, namely Medicine \& Cardiology but I am sure this observation applies to a wider array of disciplines and specialties. With the cadre of highly qualified talented specialists and administrators, as well as the dedicated and hard-working junior doctors and nursing staff, the services you provide in the hospital are second to none and what one would see in many teaching hospitals in the western world. The environment of the hospital and the infrastructure projects that have been completed have been transformative. Although it is somewhat disappointing that many Chairs in the Faculty remain unfilled, I am confident, having seen the exceptional cadre of senior lecturers in many departments, it will only be a matter of a short space of time until we see several full Professors adorning the portals of the medical faculty.

It is not my intention to address any of the current and specific operational issues that you may have in your healthcare system, since YOU are best placed to do so. However, I wish to share some ideas that could help transform any GOOD institution into a GREAT institution, so that Jaffna will take its rightful place as a Centre of Excellence not only nationally but with time, regionally in Asia Pacific and eventually in the global arena.

Looking into the past is a good way to start and to quote Winston Churchill: "the farther back you can look the farther forward you are likely to see". We often fail in our personal and societal life to build on legacies and learn from mistakes. Jaffna has a proud heritage in medical education and healthcare from the time Samuel Green established the first western medical training program at Green Memorial Hospital, Manipay in the early $19^{\text {th }}$ century. The JMA, since its inception as the Jaffna Clinical Society in 1941 has played its part in serving a society that has placed health and education as key priorities in its day to day life. It is therefore important that, even in difficult and changing times, this cultural legacy should be protected and developed further.

However, Khalil Gibran, the well-known Lebanese philosopher and poet, urges us to "embrace the past with remembrance and the future with longing" because "Life goes not backwards nor tarries with yesterday"

What do we then see when we investigate the future. We see dramatic changes in the way healthcare would be delivered. Indeed, a Healthcare Revolution is on its way. Conducting business as usual and delivering more of the same will not be good enough, however wonderful the care is in today's world. I would urge all of us to follow the Way of the Wizards. The wizards are metaphors for wisdom, and wise people are comfortable to live and respond to the unknown and the ever-changing environment. I am therefore pleased that the theme for this year's JMA session is on "Training Doctors 
for the future challenges" as it is incumbent on all of us, especially those involved with education and training, to help prepare and respond to these challenges.

Humanity has seen many such revolutions in the past. The Agricultural, Industrial and more recently the IT \& Digital Revolutions have radically changed human society. My contention is that the current Revolution in Healthcare will have similar and profound impact in the way we live in the future as a civilisation. The reason for this, is that for the first time in human history, we see the merger of the advances in biomedical sciences with that of the advances in physical sciences, namely IT \& Digital technologies. We are beginning to use digital technologies as vehicles for the global dissemination and incorporation of the biomedical advances into medical practice. Therefore, unlike in the past, the medical advances taking place in the developed world will globalise rapidly and impact on middle income and even resource poor settings.

Building capabilities and competencies in technologies per se, though very important, will NOT transform a healthcare system or its institutions into GREATNESS. For such transformation to take place, we also need to be conscious of the challenges that such technological advances will bring, including dramatic variations in the role of doctors, changing relationships with patients as well as the financial, ethical and social challenges of incorporating digital applications, artificial intelligence and robotic assistance as partners in healthcare.

Let me now touch upon certain aspects of the impact of future healthcare systems that are not well addressed in the medical curriculum. The practice of western medicine has traditionally focussed on alleviating disease and postponing death. Medical advances have, without doubt prolonged life and will continue to do so at an accelerated pace in the future. Living to reach 100 years and beyond will become the norm. Human beings have always searched for immortality or created narratives to ensure life doesn't end for them in the current form. But prolonging life is not the end of the story. It takes us to the beginning of life and the search for the meaning and purpose of life.

-4 -
We have through medical advances taken some control of our lives, but the question now being asked is whether we should have control of our death. Difficult and sensitive questions on end of life decisions and even euthanasia have complex ethical, religious and societal implications. But as a medical community, we need to engage, contribute and participate in these discussions. This will require radical shifts in the way we educate, train and prepare our doctors for these challenges. Yes, we need the competencies to manage the technological advances BUT what is needed even more is an understanding of the optimal balance between the use of technologies and the qualities that have always adorned the medical profession from the time of Hippocrates: qualities of medical professionalism and medical leadership. The focus of the medical curriculum needs to shift away from CONTENT orientation to the PRINCIPLES OF MEDICAL PRACTICE.

The process of acquiring competencies develops from the initial processing of information, through acquisition of knowledge and eventually wisdom. (Figure 1). With an increasing load of ever changing data and information, the human brain cannot compete with advanced artificial intelligence, which will increasingly provide the basic support on processing information (THE CONTENT). There is no purpose in developing a medical curriculum which is heavily content oriented that gets rapidly outdated. The purpose of education and training would be to partner with Artificial Intelligence technologies to manage the content and focus more on advancing KNOWLEDGE, developing the necessary skills and seeking to enhance our WISDOM. The equation for this progression upwards on the competency ladder involves PRACTICAL EXPERIENCE $($ Information + Experience $=$ Knowledge $)$. The purpose of the training should be to provide more opportunities to select and convert the information load through practical experiences, which could then be skilfully applied in medical practice. But the key to even GREATNESS both as individuals and as institutions is to transform KNOWLEDGE itself into discriminatory, subtle or intuitive Knowledge, namely WISDOM through LEADERSHIP practices (Knowledge + Leadership qualities $=$ Wisdom)

Vol.30, No.2, Dec. 2018 
THE COMPETENCY LADDER: FROM TECHNOCRATS to LEADERS

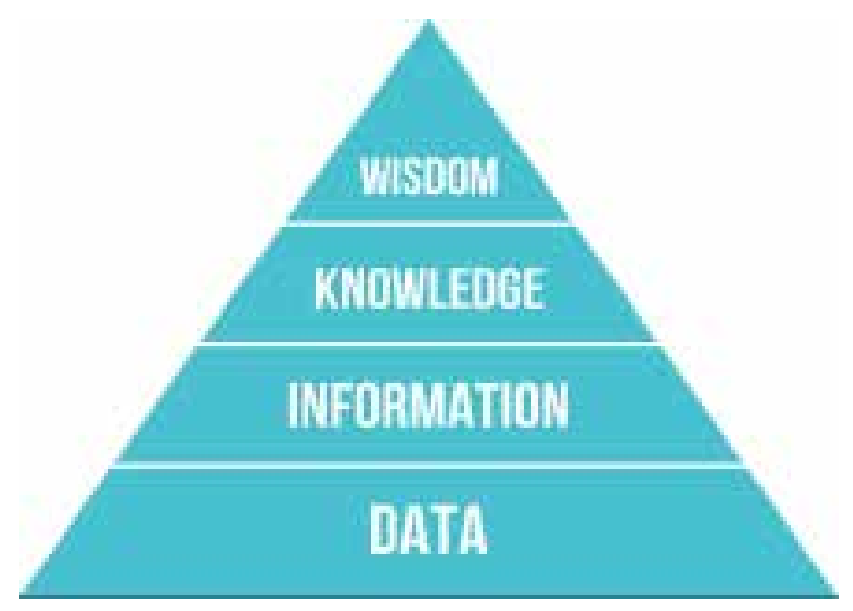

The term Wisdom is often misunderstood to be the purview of only the elderly. Yes, age and experience may make us wiser, but it is a tragedy if everyone waits until the years go by to accumulate wisdom. Every human being at all ages has the potential to be a Leader and to be Wise.

It is not my intention to conduct a Leadership course or seminar but to highlight some select principles. Firstly, "The wisdom of all wisdoms is the wisdom of HUMILITY". As Socrates said, "The only true wisdom is in knowing that you know nothing". This attitude allows us to be ready to learn in new and complex environments and to think before acting. We begin to learn from our mistakes and, in all aspects of our personal and professional lives, we become uncompromising in maintaining decent human values. But the best way of understanding and inculcating the qualities of Leadership is by learning from the Leaders who have adorned human history and enriched our lives: a Gandhi, a Mandela and an Abraham Lincoln. You may quite rightly question the futility of this personal aspiration for mere mortals like us. BUT, even if we develop a small percentage of the quality of compassion of Gandhi or the sense of forgiveness of Mandela or the courage of Lincoln, we should be well on our way in the right direction

Even if we don't succeed in developing high Leadership qualities, we must be careful NOT to become "Pseudo Leaders". Both Hitler and Stalin had semblance of Leadership qualities. They were charismatic, had long term strategic vision and were able to rally their followers towards a specific cause. BUT their intension was wrong and deceitful, and they took their followers in the wrong direction and to the wrong destination. Becoming a medical doctor comes with responsibilities. Even today, the medical profession carries considerable power and influence: the power of knowledge, the power of healing and the power of fame \& status in society. This could lead, perhaps unwittingly, to what has been called the Hubris Syndrome, excessive pride and self-confidence. We must be very conscious of this path, so that we do not become the wrong type of role models to young and aspiring doctors.

One of the key features that differentiates the LEADERS from PSEUDO LEADERS is clearly articulated in a beautiful statement from one of the greatest American Presidents, Quincy John Adams: "If your actions inspire OTHERS to dream more, learn more, do more \& become more, then, you are a Leader". In contrast, the focus of Pseudo Leaders is on themselves. Mandela himself said "It is better to lead from behind and to put others in front, especially when you celebrate victory and when nice things occur. You only take the front line when there is danger and under difficult circumstances. Then, people will appreciate your leadership." Leading from behind is a very strong leadership trait, a quality seen in a pack of wolves on a trail. The behavioural scientists have noted that the Leader of the pack stays behind, helping, guiding and supporting the other members of the pack. The elderly, the infirm and the vulnerable are kept in the front of the pack. An important lesson easily transferred to medical practice.

Indeed, the Homo sapiens, has a lot to learn from the animal kingdom: the strength in numbers from the bacteria, the work ethic of the insects, the adaptability to thrive under different circumstances from the amphibia and so on. As Deepak Chopra has said: "we have become children of science, logic and reason BUT orphans of wisdom." We have sent men to the moon and mapped the human genome but have lost the wisdom that our forefathers had in abundance.

It is worth noting the considerable differences in characteristics that separate good or even great Managers from Great Leaders. Unfortunately, there is a reluctance amongst the medical profession to see themselves as Managers or even Leaders. These roles are often delegated upwards to the Heads of Institutes or Heads of Departments. 
This assumption cannot be further from the truth. Medical Professionals by nature are good managers. We deliver on our job plan in most cases quite efficiently. Great managers delegate effectively to competent juniors and manage to prioritise their time effectively. BUT, developing Leadership qualities is a different ball game. It is all about being Visionary, being strategic in planning and preparing for the future, being trustworthy as well as being creative. Such qualities will not only help to transform us individually, but also transform our organisations and institutions, as well as the wider society. The secret to medical leadership is bring together the activities of being a good medical manager (managing our work with patients, colleagues and staff) with the additional focus in developing the qualities of leadership, medical professionalism and indeed wisdom.

The question is often asked whether these Leadership qualities can be acquired or developed or whether these are qualities that are inherent in specific individuals or genetically determined. Using a cricketing analogy, brilliant cricketers of the calibre of a Kohli, a Tendulkar or a Sangakkara are indeed born with some innate talent but the talent is only manifested to its full potential with hard work, practice and importantly, by the creation of the right environment and attitude. I am firmly of the view that every human being has the potential to develop leadership qualities, perhaps some more than the others, but the potential is always there. Leadership qualities cannot be developed through seminars or courses, although they do play a part in understanding the principles that can be put into practice. The key is to create an environment that will facilitate the development of these qualities. Unfortunately, a busy clinical practice or an academic role by themselves are not very conducive environments for leadership development. We get so caught up in our day to day tribulations of looking after patients, teaching students or writing research publications, that there is no time to pause and reflect. My advice has always been to play the 80: 20 rule. To ensure that we allocate about $20 \%$ of our professional time to activities outside our day job and job plan. We should embark on tasks that share our time with others, by being active mentors on medical professionalism, involving in cross functional projects outside our own sphere of interest or control, setting up measures to improve productivity of our institutions. Developing these institutions is not the sole responsibility of the Hospital Director or the Dean of Medicine. Such involvement is a good way of moving outside our own little box of expertise and our own individual aspirations, by giving time to others and attempting to improve the quality of our institutions. It is a great Sadhana, a great WAY of developing the qualities of leadership. It is all about BLURRING THE BOUNDARIES between ourselves, our own function and the rest of the institution and indeed the rest of society. Blurring of Boundaries between doctors and nurses, between physicians and nonphysician scientists, between hospital and the faculty staff, between clinicians and administrators; the blurring opportunities are endless. This of course needs to be done without abdicating, in any way, our own roles and responsibilities. Not an easy task but developing Leadership qualities is NOT an easy end game. But, the benefits to the individual, to the institution and to the wider society will be transformative.

But to do so, the Institutional Culture also needs to transform. The word CULTURE is often misunderstood. A culture is only a set of qualities that are common to any group of people living and working together. It is therefore essential to identify and develop an Institutional Culture. Culture is never cast in stone and is dynamic in nature. The innovation of today becomes the culture of tomorrow. The key is to develop a new culture that is transformative without changing basic human values. Values, unlike culture, are universal and eternal.

I would put it to you that the single most important determinant of a GREAT institution is it's Institutional Culture. In creating any culture of change, it is also important to note that we need the COURAGE, the PERSERVERENCE and the FOCUS to change the things we can, but also need the PATIENCE and the CALMNESS to accept the things that we cannot change, but most importantly, we should strive to develop the WISDOM to know the difference between the two - what we can change and what we cannot. And as Vince Lombardi, a simple but talented football coach said: "Perfection may be unattainable but if you chase perfection, you could at least catch excellence" 
Ladies \& Gentleman, Medical education and the delivery of healthcare in Jaffna has come a long, long, way. The JMA and its members should be proud of their own contributions to this journey. I have tried to share some of my own experiences and thoughts as to how, in the coming years, your healthcare environment could transform by creating Centres of Excellence, that are widely recognised and appreciated locally, nationally and internationally. And in all our personal and professional endeavours, we should take a leaf from the red cells. The red cells do not have a nucleus and as such, they do not possess, what some geneticists label, the SELFISH GENES seeking survival at all costs. The red cells come to life, serve every other cell in the body, carrying the vital $\mathrm{O} 2$ day in and day out, do not seek fame or even immortality and when the 120 days are over, quietly leave their world with a smile and satisfaction that the JOB has been well done. 